\title{
Oestrus synchronization with fixed-time artificial insemination in smallholder pig production systems in north-east India: Success rate and benefits
}

\author{
G. Kadirvel ${ }^{1 \#}$, K. M. Bujarbaruah ${ }^{2}$, Suresh Kumar ${ }^{1}$ \& S. V. Ngachan ${ }^{1}$ \\ ${ }^{1}$ Division of Animal Production, ICAR Research Complex for NEH Region, Umiam, Meghalaya-793 103, India \\ ${ }^{2}$ Assam Agricultural University, Assam, India.
}

(Received 7 March 2014; Accepted 3 January 2017; First published online 27 January 2017)

\begin{abstract}
Copyright resides with the authors in terms of the Creative Commons Attribution 4.0 South African License.
See: http://creativecommons.org/licenses/by/4.0/za

Condition of use: The user may copy, distribute, transmit and adapt the work, but must recognize the authors and the South African Journal of Animal Science.
\end{abstract}

\begin{abstract}
Pig production is an important component of the farming systems that are practised in the northeastern region of India and it has special significance for improving the socio-economic status of tribal farmers in the region. In an effort to optimize the production efficiency of rural pig production systems, the potential influence of oestrus synchronization and fixed-time artificial insemination (AI) on synchronizing husbandry programmes was investigated. A total of 117 crossbred sows, selected from various village production units, were randomly allocated to two (control and treatment) groups. The sows in the treatment group $(n=81$ ) received $800 \mathrm{IU}$ of equine chorionic gonadotropin (eCG), followed by $500 \mathrm{IU}$ of human chorionic gonadotropin (hCG) 72 hours after the eCG injection. The sows in the control group $(n=36)$ served as the untreated control. The onset of oestrus, oestrus signs, oestrus intensity, and duration of oestrus were observed after treatment. The oestrus sows were inseminated twice at $24 \mathrm{~h}$ and $36 \mathrm{~h}$, respectively, after hCG injection at various village production units. Results revealed that $86.4 \%$ of sows in the treatment group exhibited all the behavioural and physical signs of oestrus. The average interval between treatment and onset of oestrus was $84.8 \pm 2.43$ hours. The mean oestrus intensity of sows in the treatment group was 2.3 (when assessed on a scale of 1 to 3 ), which did not differ significantly from the oestrus intensity exhibited by the control group. The duration of oestrus varied from 36 to 56 hours in the treated sows, which was significantly longer when compared with the duration of oestrus in the control group. The study obtained a farrowing rate of $82.6 \%$ and litter size of $9.2 \pm 0.32$ after oestrus synchronization with timed insemination. Oestrus synchronization facilitated the insemination of a batch of sows at particular locations covering two to three village clusters, which drastically reduced the transport costs for the semen. Oestrus synchronization facilitated the effective implementation of Al by coordinating the insemination of batches of sows, thus reducing shipping and insemination costs. Improving heat detection contributed to shortening the weaning to oestrous interval in smallholder pig production system, which in turn decreased production costs.
\end{abstract}

Keywords: Assisted reproduction, farrrowing rate, insemination cost, reproduction efficiency

\#Corresponding author: velvet.2007@rediffmail.com

\section{Introduction}

The north-eastern region of India is dominated by tribes whose staple diet is pork. Pig farming can play an important role in improving the socio-economic status of farmers in the region. India has a swine population of 13.52 million and this region contributes to $28 \%$ of the country's total pig population (Bujarbaruah, 2005). On average, a rural household rears two or three pigs in their backyard. A typical smallholder low-input pig production system consists of a simple pigsty made up of bamboo or wooden planks/poles. Feeding consists of locally available grains, vegetables and agricultural by-products, along with kitchen waste. Rural pig production systems are also characterized by the non-availability of quality boars, high mating costs, increased interval from weaning to next service, increased non-productive days, and ultimately low reproductive efficiency. Similar low-input smallholder production pig systems have been reported in Africa and South East Asian countries (Lemke et al., 2007; Kagira et al., 2010; Riedel et al., 2012).

Recently, Al with semen from superior boars has been introduced for the genetic improvement of nondescript pigs. The multiple benefits in smallholder pig production systems have been documented by 
Kadirvel et al. (2013). However, high semen transport costs and poor oestrous detection are the major limitations in the Al implementation programme. High semen transport costs are mainly owing to the scattered distribution of villages and farmers in poorly accessible hilly forest terrains. Oestrus synchronization with timed Al would be a viable option to reduce insemination costs and improve oestrus detection in smallholder production systems.

Although the practice of oestrus synchronization has been applied frequently in the commercial swine industry to increase the number of litters per sow per year (Kirkwood \& Thacker, 1998; Estill, 2000; Brüssow \& Wähner, 2011), there is no report about oestrus synchronization with timed Al and its benefits in smallholder pig production systems in India. So the present study was undertaken to assess the potential, feasibility, success, and benefits of oestrus synchronization with fixed-time Al in rural smallholder pig production systems in north-east India.

\section{Materials and Methods}

The study was carried out after approval by the Animal Ethics Committee of the Indian Council of Agricultural Research (ICAR) complex for NEH region, Umiam, Meghalaya, India (No. $\mathrm{RC} / \mathrm{BP} / \mathrm{AH} / 41 / 2009 / 1520$, dated 20 August 2012 by Institutional Animal Ethics Committee). NEH region is located between $91^{\circ} 55^{\prime} \mathrm{E}$ longitude and $25^{\circ} 40^{\prime} \mathrm{N}$ latitude in the state of Meghalaya, India. The study site is situated at $1010 \mathrm{~m}$ above sea level and receives annual rainfall of 2239 to $2953 \mathrm{~mm}$. The annual maximum and minimum temperatures range from $21.1^{\circ} \mathrm{C}$ to $29.2^{\circ} \mathrm{C}$ and from $7.0^{\circ} \mathrm{C}$ to $20.9{ }^{\circ} \mathrm{C}$, respectively. The average relative humidity of the region ranges from $71.1 \%$ to $88.3 \%$ in the morning to $41.7 \%$ to $73.7 \%$ in the afternoon. The study site is characterized by hilly topography, and most of the area is occupied by typical tribal farming systems, of which pig production contributes a significant proportion of farming activities. The study was conducted in 11 villages that are located within $15-20 \mathrm{~km}$ of ICAR.

A total of 117 nondescript sows (2-4 years old), which were not showing signs of oestrus 15 days after weaning, were selected in the villages and randomly allocated to the treatment group (Group I) $(n=81)$ and the control group (Group II) $(n=36)$. Bodyweight of the sows ranged from 87 to $157 \mathrm{~kg}$. The sows were reared in low-input traditional production systems. That is, they were kept in an indoor pen system, which was constructed from locally available materials such as wooden planks and bamboo poles, with a tin roof as protection over the covered area of the pigsty. The sows were fed with local vegetable agro-waste and household kitchen waste. The kitchen waste included vegetable peel, fruit peel and small amounts of waste cooked food. Commonly used non-conventional pig feeds were sweet potato (Ipomoea batatas), colocasia (Colocasia esculenta), tapioca (Manihot esculenta), pumpkin (Cucurbita maxima), bamboo (Bambusa balcooa) shoots, and leaves and stems of banana plants (Musa acuminata). The leaves and stems of plants were cooked and mixed with rice bran, wheat bran, broken rice and kitchen waste. The study ensured that the selected sows were not mated before treatment.

The sows in Group I received 800 IU of eCG (Folligon, Intervet India Pvt Ltd, India) followed by 500 IU of hCG (Chorulon, Intervet India Pvt Ltd, India) 72 hours after eCG injection intramuscularly according to the protocol described by Breen et al.(2005) and Patterson et al. (2010). It is the most successfully used protocol for oestrus synchronization in the commercial pig industry (Kraeling \& Webel, 2015). The sows in Group II served as the untreated control. The onset of oestrus after treatment, oestrus signs, oestrus intensity, duration of oestrus, standing reflex and duration of standing oestrus were observed for the sows. Oestrus detection was performed by technicians twice daily at 06.00 and 16.00 by visual examination to assess the oestrus response. Oestrus intensity was measured visually. The standing reflex was assessed by the back pressure test by experienced technical personnel according to the procedure described by Sterning (1995). The intensity of oestrus was scored from 0 to 3 , based on the degree of reddening and swelling of the vulva $(0=$ no reddening or swelling; 1 = light degree of reddening and swelling; 2 = moderate reddening and swelling; and 3 = extensive reddening and swelling) and an average score was compared between the groups. The oestrus duration was calculated as the period between the appearance of oestrus signs and complete disappearance of the signs. Duration of standing oestrus was calculated as the period in which the sows exhibited the standing reflex during oestrus.

Al was performed with diluted semen preserved at $18{ }^{\circ} \mathrm{C}$. Briefly, semen samples were collected from Hampshire boars with the gloved hand technique in the presence of a dummy sow (IMV technologies, France). The gel-free semen was used for further processing and preservation. After physical and morphological evaluation, ejaculates exhibiting more than $70 \%$ sperm motility were diluted with Beltsville thawing solution (BTS) $(0.2 \mathrm{M}$ glucose, $0.02 \mathrm{M}$ sodium citrate, $0.015 \mathrm{M} \mathrm{NaHCO}$, $3 \mathrm{mM}$ EDTA, $0.01 \mathrm{M} \mathrm{KCl}$, $\mathrm{pH}$ 7) (Pursel \& Johnson, 1975) at a $1: 3$ ratio. The diluted semen was stored at $18{ }^{\circ} \mathrm{C}$ in a biochemical oxygen demand (BOD) incubator (Narang Scientific Works, 122 Pvt Ltd, New Delhi, India). The extended semen samples were used within 12-14 $\mathrm{h}$ of storage for on-site insemination of sows at the localities. The extended semen samples were maintained at $18 \stackrel{\circ}{\circ} \mathrm{C}$ and transported to the villages in a portable 
temperature-controlled system (cell incubator, Welson, Korea). The sows that displayed confirmed signs of oestrus were inseminated twice at $24 \mathrm{~h}$ and $36 \mathrm{~h}$ after hCG injection with a Goldenpig catheter (IMV Technologies France). About $80-100 \mathrm{ml}$ semen volume, containing three billion sperm, were used per insemination dose. The farmers were advised to observe the inseminated pigs for a recurring heat cycle after 18-22 days post insemination for tentative confirmation of pregnancy. The inseminated non-cycling pigs were diagnosed for pregnancy at six weeks after insemination by the Doppler method (Maes et al., 2006). Farrowing rate (number of sows that farrow divided by the number sows inseminated), litter size at birth (total number of piglets born per farrow), number of live piglets born per litter (total number of live piglets born per farrow), litter weight at birth (individual birth weight of piglet at birth), and litter size at weaning were recorded.

Data on oestrus response, oestrus behaviour and reproductive performance recorded for the control and treatment groups were analysed for statistical significance $(P<0.05)$ by comparing the means through multiple ANOVA (LSD and Duncan multiple range test) of SPSS (version 13.0). Data were expressed as means \pm SE.

\section{Results}

The oestrus responses of sows to the hormonal treatment are shown in Table 1. Oestrus behaviours and signs such as swollen and congested vulva lips, homosexual activities, presence of sticky mucous discharge from the vulva, and standing reflex were recorded in $75 \%$ of sows after $72 \mathrm{~h}$ of eCG injection. A total of $86.4 \%$ of sows exhibited all the signs of oestrus, including standing reflex after $96 \mathrm{~h}$ of eCG treatment. In the untreated control group, of 36 sows, $9(25.0 \%)$ sows exhibited oestrus signs during the study period, which is lower $(P<0.01)$ than that observed in Group I (Table.1). The interval from the administration of hormonal treatment to onset of oestrus varied from 56 to 102 hours with an average of 84.8 \pm 2.43 hours. The average oestrus intensity score assigned to the sows from Group I amounted to 2.4, which did not differ significantly from the control group (2.3, $P<0.05)$. The duration of oestrus varied from 36 to 56 hours with an average of $45.8 \pm 1.34$ hours in the treated group and ranged from 27 to 52 hours in the control group. The duration of oestrus is significantly lower in the control group $(34.5 \pm 1.45, P<0.05)$ compared with the treated group.

Table 1 Oestrus synchronization response with equine chorionic gonadotropin followed by human chorionic gonadotropin in sows reared under smallholder production system (mean $\pm \mathrm{SE}$ )

\begin{tabular}{lcc}
\hline Parameters & Treatment & Control \\
\hline Number of sows treated & 81 & 36 \\
Percentage of sows responded to treatment (no. of sows) & $86.4(70)^{\mathrm{a}}$ & $25.0(9)^{\mathrm{b}}$ \\
Average treatment to onset of oestrus interval (h) & $84.8 \pm 2.43$ & - \\
Average duration of oestrus (h) & $45.8^{\mathrm{a}} \pm 1.34$ & $34.5^{\mathrm{b}} \pm 1.45$ \\
Oestrus intensity & & \\
$\quad$ No. of sows scored -1 & 25 & 4 \\
No. of sows scored -2 & 37 & 4 \\
$\quad$ No. of sows scored -3 & 2.4 & 2.3 \\
$\quad$ Average score & $28^{\mathrm{a}} \pm 2.34$ & $52^{\mathrm{b}} \pm 5.34$ \\
Weaning to oestrous interval (days) & &
\end{tabular}

The farrowing rate recorded for Group I was $80.0 \%$, which did not differ from the control group (77.7\%) (Table. 2). The present study recorded an average litter size of $9.2 \pm 0.32$ and $8.7 \pm 0.25$ in the treated group and the control group, respectively. The cost analysis of the technology in the study indicated that the cost of hormones amounted to Indian rupee (INR) 500/pig/dose, and the cost per dose of semen was INR35 for the treated group, and INR58 for the control group. The average transport cost of the semen from semen storage unit to the various villages amounted to INR130 for the treated group, and INR950 for the control group. 


\section{Discussion}

Oestrus synchronization with fixed-time Al could be of great benefit to swine production. However, the response and effectiveness, outcome and benefits of the technique depend on hormone preparation, protocols, breed, management condition and production system (Estienne \& Hartsock, 1998; Estill, 2000; Breen et al., 2005; Patterson et al., 2010). The present study evaluated the effectiveness of eCG combined with hCG to induce oestrus in sows after weaning, followed by fixed time Al in smallholder pig production systems.

Table 2 Reproductive performance and cost benefit of oestrus synchronization with timed artificial insemination (AI) in sows reared under smallholder production system (mean $\pm \mathrm{SE}$ )

\begin{tabular}{lcc}
\hline Parameters & Treatment & Control \\
\hline No. of sows inseminated & 70 & 9 \\
Farrowing rate (\%) & $80.00(56)^{\mathrm{a}}$ & $77.8(7)^{\mathrm{a}}$ \\
Litter size at birth & $9.2^{\mathrm{a}} \pm 0.32$ & $8.7^{\mathrm{b}} \pm 0.25$ \\
Still birth (\%) & $0.3^{\mathrm{a}} \pm 0.06$ & $0.3^{\mathrm{a}} \pm 0.05$ \\
Litter weight at birth/piglet (kg) & $0.84^{\mathrm{b}} \pm 0.35$ & $0.86^{\mathrm{b}} \pm 0.21$ \\
Litter size at weaning & $7.87^{\mathrm{b}} \pm 0.52$ & $7.98^{\mathrm{b}} \pm 0.32$ \\
Litter weight at weaning/piglet $(\mathrm{kg})$ & $8.12^{\mathrm{a}} \pm 0.77$ & $8.15^{\mathrm{a}} \pm 0.63$ \\
Bodyweight at 3 months /piglet $(\mathrm{kg})$ & $10.8^{\mathrm{b}} \pm 1.32$ & $10.9^{\mathrm{b}} \pm 0.78$ \\
Costs & & \\
Hormone cost/pig & INR 500 & - \\
Cost liquid semen/dose & INR 35 & INR 58 \\
Shipping costs & INR 130 & INR 950 \\
\hline
\end{tabular}

${ }^{a, b}$ Rows with different superscripts differ significantly $(P \leq 0.05)$.

Oestrus signs, including restlessness, reduced feed intake, swollen or congested vulva lips, homosexual behaviour, sticky mucous discharge from vulva, and standing reflex, were observed after the treatment. After hormone administration, $86.4 \%$ of sows in the treatment group exhibited standing oestrus, which agrees with earlier findings in the commercial swine industry (Breen et al., 2004; Patterson et al., 2010). Since estradiol is responsible for the behavioural changes associated with oestrus (Roy \& Prakash, 2009), the observed oestrus signs in the study are indicative of a rise in circulating estradiol levels owing to rapid follicular growth after the hormonal treatment. A distinct oestrus period with strong symptoms is necessary to determine the optimum time for insemination. In the present study, most of the sows (80\%) exhibited moderate to strong oestrus intensity when scored for the level of intensity. The duration of oestrus was significantly longer $(P<0.05)$ in synchronized sows than in the untreated sows. The longer duration of oestrus in the treated group may be because of the longer half-life of eCG (Hafez \& Hafez, 2006). Similarly, a longer duration of oestrus was observed with the use of eCG (Mohammad et al., 2011).

Al after synchronization of oestrus with eCG and hCG resulted in a satisfactory farrowing rate and litter size in the smallholder pig production systems in the study (Table.2). The farrowing rate and litter size recorded in the study are within the ranges reported for the commercial pig industry (Estienne \& Hartsock, 1998; Patterson et al., 2010). The significantly larger litter size in the treated groups compared with the control group is in agreement with the findings of Estienne \& Hartsock (1998) and Patterson et al. (2010). The longer half-life of eCG may be responsible for the prolonged period of follicular stimulation, which resulted in a higher number of ova being released (Estienne \& Hartsock, 1998), which potentially resulted in the apparent increase in litter size in eCG-treated sows in the present study.

The multiple benefits of the Al biotechnology in smallholder pig production have recently been reported in the region (Kadirvel et al., 2013). The present study indicated that oestrus synchronization and fixed-time Al increased the benefits associated with Al and its application efficiency in smallholder pig production systems. Since the tribal villages are scattered in a small clusters in the poorly accessible hilly terrain, frequent transport of semen for $\mathrm{Al}$ is difficult and costly. Therefore, transport costs contribute a major part of the overall expenses associated with the use of $\mathrm{Al}$ in these systems. In the study, the synchronization 
of oestrus facilitated batch insemination at a particular location that included two or three village clusters, which reduced transport costs drastically. Poor heat detection because of lack of knowledge or awareness of oestrus signs among tribal farmers is a constraint in the pig production system. In this study, this was overcome by the synchronization of oestrus and fixed time Al. In addition, the synchronized breeding of several sows on site on the same day allowed for a reduction in semen shipping costs, and increased efficiency in utilizing the few skilled inseminators at a particular time. Because similar smallholder pig production parameters were reported in African and South East Asian countries (Lemke et al., 2007; Kagira et al., 2010; Riedel et al., 2012), this suggests that farmers in these regions could also benefit through oestrus synchronization and fixed-time Al, accompanied by a decrease in the number of non-productive days.

\section{Conclusions}

Satisfactory results in terms of farrowing rate and litter size were obtained with oestrus synchronization and fixed-time Al in smallholder production systems in this study. Improved production and reproduction efficiency would be possible if effective coordination could reduce the overall costs associated with the application of the biotechnology (shipping and insemination), and farmers were trained to improve their knowledge and skills for heat detection, which is crucial in determining the right time of insemination.

\section{Acknowledgements}

The authors thankfully acknowledge the DBT for financial support for the project and the Director: ICAR Complex for NEH Region for providing the facilities to conduct the research. The authors gratefully acknowledge Shri. H.S. Nongkynrih for translating the local language (Khasi) to English language throughout the period. The farmers at the villages are also acknowledged for their kind cooperation during the research.

\section{Authors' contributions}

GK carried out the research work and wrote the manuscript, KMB and SVN designed the research project. Data analysis and revisions of manuscript were performed by SK.

\section{Conflict of Interest Declaration}

The authors declare that there is no conflict of interest for this study

\section{References}

Breen, S.M., Farris, K.L., Rodriguez-Zas, S.L. \& Knox, R.V., 2005. Effect of age and physical or fence-line boar exposure on oestrus and ovulation response in prepubertal gilts administered PG600. J. Anim. Sci. 83,460-465.

Brüssow, K.P. \& Wähner, M., 2011. Biological and technological background of oestrus synchronization and fixed-time ovulation induction in the pig. Biotech. Anim. Husbandry 27, 533-545.

Bujarbaruah, K.M., 2005. Step towards increasing livestock production in north-eastern region of India. Research Bulletin 45. ICAR Research Complex for NEH region, Meghalaya, India.

Estienne, M. J. \& Hartsock, T.G., 1998.Effect of exogenous gonadotropins on the weaning-to-oestrus interval in sows. Theriogenology 49, 823-828.

Estill, C.T., 2000. Current concepts in oestrus synchronization in swine. J. Anim. Sci. 77, 1-9.

Hafez, B. \& Hafez, E.S.E., 2006. Reproduction in farm animals. 7th ed. Blackwell. Philadelphia, Pennsylvania

Kadirvel, G., Kumaresan, A., Anubrata, D., Bujarbaruah, K.M., Venkatasubramanian, V. \& Ngachan, S.V., 2013. Artificial insemination of pigs reared under smallholder production system in north-eastern India: Success rate, genetic improvementand monitory benefit. Trop. Anim. Health Prod. 45, 679-686.

Kagira, J.M., Kanyari, P.W.N., Maingi, N., Githigia, S.M., Ngana, J.C. \& Karuga, J.W., 2010. Characteristics of the smallholder free-range pig production system in Western Kenya. Trop. Anim Health Prod. 42, 865-873.

Kirkwood, R. \& Thacker, P., 1998. Induced oestrus and breeding during lactation: Effects on sow and litter performance. J. Swine Health Prod. 6, 95-98.

Kraeling, R.R \& Webel, S.K., 2015. Current strategies for reproductive management of gilts and sows in North America. J Anim Sci Biotechnol. 31, 6(1):3. doi: 10.1186/2049-1891-6-3.

Lemke, U., Kaufmann, B., Thuy, L.T., Emrich, K. \& Zárate, A.V., 2007. Evaluation of biological and economic efficiency of smallholder pig production systems in North Vietnam. Trop Anim Health Prod. 39, 237-54.

Maes, D., Dewulf, J., Vanderhaeghe, C., Claerebout, K., De Kruif, A., 2006. Accuracy of trans-abdominal ultrasound pregnancy diagnosis in sows using a linear or sector probe. Reprod. Domest. Anim. 41, 438-443.

Mohammad, A.S., Mohammad, H.S., HamidMorad, P.E. \& Hamed, K.M., 2011. The effects of pregnant mare serum gonadotropin (PMSG) injection a day prior or at controlled intravaginal drug-releasing (CIDR) removal on multiple births in Afshari ewes. Afr. J. biotechnol. 10, 12363-12367.

Patterson, J.L., Cameron, A.C. \& Smith, T.A., 2010. The effect of gonadotropin treatment at weaning on primiparous sow performance. J. Swine Health Prod. 18, 196-199.

Pursel, V.G. \& Johnson, L.A.,1975. Freezing of boar spermatozoa: Fertilizing capacity with concentrated semen and a new thawing procedure. J. Anim. Sci. 40, 92-102. 
Riedel, S., Schiborra, A., Huelsebusch, C., Huanming, M. \& Schlecht, E., 2012. Opportunities and challenges for smallholder pig production systems in a mountainous region of Xishuangbanna, Yunnan Province, China. Trop. Anim. Health Prod. 44, 1971-80.

Roy, K.S. \& Prakash, B.S., 2009. Plasma progesterone, oestradiol-17 $\beta$ and total oestrogen profiles in relation to oestrous behaviour during induced ovulation in Murrah buffalo heifers. J. Anim. Physiol. Anim. Nutr. (Berl). 93, 486-95.

Sterning, M., 1995. Oestrous symptoms in primiparous sows. 2. Factors influencing the duration and intensity of external oestrous symptoms. Anim. Reprod. Sci. 40, 165-174. 